\title{
Emerging Trends and Future Perspective of Human Resource Reskilling in Higher Education
}

\author{
B. Suhasini, Dr. Santhosh Kumar N
}

\begin{abstract}
The emerging trends and the fast changing Technology across all fields demands for continuous learning and upgrading the skills of human resources across the world, for sustaining the global completion and performing better in the global economies. The employee resources of any organization should be well oriented towards the upcoming technologies such as Artificial Intelligence, Big data, Machine Learning, Communication Technologies etc relevant to their respective work operations and should be prepared and facilitated to gain knowledge. Organization across all industry sectors should have a Strategy and action plan put in place for facing such cultural changes and providing regular reskill training sessions among its human resources for the benefit of employee and organization development which in turn helps for effective customer relationship management and services delivery.

The Higher education institutions also required to focus strongly on reskilling their human resources in order to enhance value proposition in programme delivery and building customer relationship with its various stakeholders such as faculty, students, industry experts etc with changing scenario of economic, technological, and cultural environment. The article further highlights the impact and usefulness of Reskilling various stakeholders with emerging technologies relevant to Higher education making the youth competent to face the challenging future.
\end{abstract}

Index Terms: Reskilling, CRM, Higher education, Digital Systems, Competency building.

\section{INTRODUCTION}

The emerging trends and the fast changing Technology across all fields demands for continuous learning and upgrading the skills of human resources across the world, for sustaining the global completion and performing better in the global economies. The industry sectors are getting reshaped day by day with evolution of new technologies like advanced robotics, Internet of Things. The smart algorithms and machines learning are more capable than the humans, the work load is being transformed drastically in manufacturing or agricultural sectors replacing the traditional methods. The business processes in the financial, healthcare sectors have seen significant changes in the operations that are been carried out both offshore and onsite with the use of advanced business intelligence and strong security tools. The Hospitality and retailing also seen impact of technological

Revised Manuscript Received on July 05, 2019

B. Suhasini, School of Management, SRM Institute of Science and Technology, Kattankulathur, Tamil Nadu.

Dr. Santhosh Kumar N, School of Management, SRM Institute of Science and Technology, Kattankulathur, Tamil Nadu. changes and could accelerate their business models using cloud technology, redesigned the customer service delivery strategy with integration of digital social networking platforms for better reach of customers any time.

The employee resources of any organization should be well oriented towards the upcoming technologies such as Artificial Intelligence, Big data, Machine Learning, communication technologies etc relevant to their respective work operations and should be prepared and facilitated to gain knowledge on such emerging technologies in the field of digitization and advanced automation systems that are guiding and taking the world forward. With the increasing absorbing capability and acceptance of new emerging systems by the manpower in the organizations, are helping the organizations to carry out the day to day business tasks with less hassles. Organization across all industry sectors should have a Strategy and action plan put in place for facing such cultural changes and providing regular reskill training sessions among its human resources for the benefit of employee and organization development which in turn helps for effective customer relationship management and services delivery.

In order to catch up with industry competition due to changing scenario of economic, technological, and cultural environment across the world, the Higher education institutions also required to focus strongly on reskilling the human resources in the organization to enhance the value proposition of the academic and business services delivery. In the age of digitization and automation, building sustainable customer relationship with various stakeholders such as faculty, students, industry experts etc is always a top priority for global educational institutions for knowledge creation and industry exchange process. Higher education institutions being the source to produce young minds with lot of creativity and entrepreneurial ideas, and act as knowledge hub for inducing the latest technologies relevant to various industry sectors, plays a major role in fulfilling the skill gap.

The article further highlights the impact and usefulness of Reskilling various stakeholders with emerging technologies relevant to Higher education for prospective future and making the youth more competent to face world challenges with ease.

What is Reskilling?

Reskilling is the process of educational training delivery of traditional theoretical

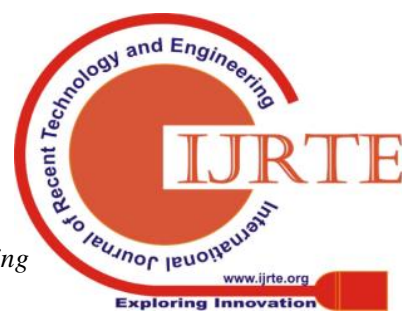


concept added with applied learning methods suitable for industry needs with appropriate pricing and providing the workforce the opportunity towards new career pathway. The skill demanded by the workforce is being altered with demographic shift gap and technological innovation in most of the countries. The international organizations, industry experts, academicians and corporate business leaders feel that skill gap arising due to fourth industrial revolution need to be tackled on top priority and invest in retraining the workforce of all age groups as per the job requisition for desired organizational results. There should be right educational and balanced training ecosystem providing the career prospects relevant to industry needs. This requires a great amount of team work and collaboration with multiple stakeholders, policy makers, global industry leaders to brainstorm and put in the policy and systems in place to meet the changing demand of the world.

According to Mckinsey Global Institute Report (2018) the $14 \%$ of world's work force may have to change their respective job category with the emerging technologies of digitization, automation and artificial intelligence etc that are going to bring massive change in the work culture and business operations by 2030 . The survey conducted by the Mckinsey reveals that $62 \%$ of executives across the globe strongly believe that the retraining and replacement of their workforce is needed by 2020 due to advancing automation and digitization process and systems in work places. The demand seems to be high in United States (64\%) and Europe $(70 \%)$ than the rest of the world (Only 55\%). $70 \%$ of executives from the bigger companies across the globe predict that more than a quarter of their workforce may get affected in next five years with technological disruption.

It is been observed by the Organization for Economic Co-operation and Development (OECD), that many countries fail to respond to the skills gap challenges due to factors such as quality of education and the cost incentives of incorporating automation. According to NASSCOM, In India, close to $40 \%$ of the country's four million IT workforce will need reskilling in the coming years to keep up with the accelerating pace of technological developments in areas such as automation, analytics and machine learning. As a solution, all the companies are increasingly looking forward for investing in retraining and reskilling existing human resource, as an urgent business priority to meet the potential skill gap in order to face the technological challenges that are critical for continuing the future business operations and sustain the competition.

Re-skilling Process in Higher education Faculty:

Faculty and Academic experts should consider for bringing newer learning models, while planning and designing the academic programmes or skill development programmes relevant to industry professionals and students. The learning ecosystem should be blended with active and experiential learning methods with relevant modular contents for ease of understanding, absorption and practice. The blended learning environment with well integrated digital communication platforms will provides active participation and facilitate the exchange of ideas through meaningful debate in online discussion forums. The faculty should be well equipped and prepared to get adapted with new functionality of latest technology of digital and social CRM platforms that are been used in such blended learning environment. The faculty

should bring in the new learning style for providing the peer to peer learning structure online. In many countries, Internet-based online instructional delivery is now the fastest growing in higher education. Massive Open Online Courses (MOOCs) technology platforms provided opportunity to faculty community across top universities to teach their advanced skill based courses to many number of students and professionals. Integration of digital technology in research collaboration and exchange of subject matters with industry experts will enhanced the research outcome of the faculty community. The active participation by the faculty members in various digital initiatives, social networking forum and contribution to various digital technology platforms helps in knowledge sharing. A system that is dynamically linked with students, faculty curriculum planners etc gives a different student learning experience than formal way of classroom teaching.

Students - The technology became integral part of any learning environment. The demand for anytime and anywhere access to information among the student constituents through various service touch points such learning platforms, application portals that provide access to student community for their academic and administrative transactions. The communication channels between student services and faculty community are made more virtual and instant than earlier days. The student's progression in entire student life cycle from prospect to admit to alumni involves complex interaction through cutting edge technology at each stage. Particularly, students being technology-savvy, who are inclined towards more of self-learning these days, expect the self-driven learning platforms and communication channels for their academic progress. They intend to choose the institutions that meet their area of interest on their own terms, meeting their learning schedules. These are achieved only when the effective digital learning tools and sophisticated IT mobility infrastructure support systems are in place.

\section{Business Process Owner/Administrative Staff}

The administrators, particularly the Marketing team of education institutions need to be reskilled with latest technology platforms of CRM, social networking etc in addition to communication and presentation skill. The world competition for education industry put forth the demand for acquiring the skill set and knowledge in terms of data science and business intelligence for knowing the pulse of prospective applicants or professionals of their educational requirements.

The automation systems such as ERP/CRM intend to introduce a true self-service system that empowers the administrative team to carry out the administrative activities efficiently. This helps the administrative staff focusing on more productive, rewarding, and customer satisfying activities. This helps them to complete all business processes, such as making personal connections with students, faculty and staff, external academic experts, maintain their information from time to time, providing secured access to vital information as and when business transaction is needed. For colleges and universities, well-defined service touch point processes integrated with electronic online payment systems enhances the business digital services transactions and increases business revenue with the increased enrollment, recruitment and retention. 


\section{CONCLUSION}

\section{Re-skilling for effective Customer Relationship Management in Higher Education}

The CRM based digital learning platforms play a major role in reskilling process by replacing the traditional methods such as

- Physical classroom are transformed with virtual interactive learning platforms driving towards institutional continuous learning process.

- The text book and traditional examinations are now more been handled with the use of cloud based computing, mobile apps, advanced 3D systems providing access to visually rich content and digital online examinations for quicker assessments and learning progress

- Certification courses are enhanced and facilitated with internationally recognized university Tie-ups and delivering through MOOC courses that are customized and made available relevant to industry needs with rich experiential and virtual lab practices.

- Traditional Seminars and conferences are more becoming as Techfest events, Gamification and Hackathons bringing real time experience in colloquium learning.

The academic institutions moving ahead with e-business and e-learning technologies, as the driving forces using CRM system for stronger and effective services delivery.

India has huge opportunity for fill up the skill gap with the advantage of having world's largest young population in the country (As per UN Report 2014). NASSCOM believes the IT industry's current reskilling focus is on emerging technologies like Big Data, Analytics, Cloud, IoT, Mobility, and Design Thinking, while also investing in emerging skills like Machine Learning, Natural Language Processing, Artificial Intelligence, DevOps, Robotic Process Automation, and Cybersecurity. The education institutions should identify right courses relevant to the industry by incorporating the new age learning methodologies, digital skilling platforms for future changes and enabling the programme delivery more user friendly and making the youth ready for catching up the competition and job opportunity across the globe.

\section{REFERENCES}

1. Pablo Illanes, Susan Lund, Mona Mourshed, Scott Rutherford, and Magnus Tyreman, Retraining and reskilling workers in the age of automation, Jan 2018, McKinsey Global Institute.

2. Accelerating Workforce Reskilling for the Fourth Industrial Revolution An Agenda for Leaders to Shape the Future of Education, Gender and Work, World Economic Forum, 2017

3. Ranjan Kumara and Neerja Pande, Technology-mediated learning paradigm and the blended learning ecosystem: what works for working professionals? Procedia Computer Science 122, 2017, 1114-1123.

4. Skilling for Digital Relevance, NASSCOM, 20 July 2017.

5. Marianne Georgsen, Charlotte Vange Løvstad, Use of blended learning in workplace learning, Procedia - Social and Behavioral Sciences 142, $2014,774-780$

6. Manfred Kochen, Yufei Yuan, and Charles Barr, On the Value of Human Resources, TECHNOLOGICAL FORECASTING AND SOCIAL CHANGE 30, 1986, pp. 93-110.

7. Building a workforce of the future - up skilling/reskilling in global In-house centers, Everest Group Research Report, Dec 2017

8. Paula McIver Nottingham, "Re-evaluating work-based learning pedagogy", Higher Education, Skills and Work-Based Learning, Vol. 7 Issue: 2, 2017, pp.129-140
9. Sheila Kloefkorn, It's Time To Reskill The Marketing Workforce, April 2018, Forbes

10. Education at a Glance, 2018, OECD INDICATORS 